\title{
Estratégias de Inserção e Permanência na Rede de Trabalho em Tecnologia da Informação
}

Strategies for Insertion and Permanence in the Information Technology Network

Marcos José Valle ${ }^{1}$

${ }^{1}$ Centro Universitário Autônomo do Brasil, UniBrasil 


\title{
Resumo
}

O objetivo deste artigo é analisar as configurações de trabalho na área de Tecnologia de Informação, visando identificar estratégias de inserção e permanência de profissionais no mercado de trabalho organizado em rede. Utiliza metodologia qualitativa valendo-se de entrevistas semiestruturadas com quatro profissionais do setor, todos da cidade de Curitiba e Região Metropolitana, estado do Paraná, analisados sob a Teoria dos Grafos e observada a construção dos Laços Fortes e Laços Fracos e a superação de Buracos Estruturais. Os entrevistados selecionados para a amostra apresentam situações das quais se beneficiam por meio das cadeias relacionais curtas, laços fortes, e dos laços fracos pela enfatize de suas competências profissionais e como são lembrados. Conclui-se que os profissionais do setor enfrentam forças de oferta e demanda em um mercado cujo fator de produção e mercadoria de troca é o conhecimento, sob o risco constante de insucesso em permanecerem atuantes com base na disponibilidade de oportunidade combinadas ao esforço intensivo necessário para atuação.

Palavras-chave: tecnologia de informação, rede, teoria dos grafos, laços forte, laços fracos, buracos estruturais

\begin{abstract}
The purpose of the article is to analyze working configuration in the Information Technology área. It was aimed to identify strategies for insertion and permanence of professionals in the labor market organized in a network. Qualitative methodology using semi-structured interviews with four professionals in the sector was used, being all from the city of Curitiba and Metropolitan Region, state of Paraná, and were analyzed under the Graph Theory and observed the construction of Strong Ties and Weak Ties and the overcoming of Structural Holes. The interviewees selected for the sample present situations that they benefit from through short relational chains, strong ties, and weak ties by emphasizing their professional skills and how they are remembered. It is concluded that the professionals of the sector face forces of supply and demand in a market in which factor of production and exchange goods are considered knowledge, under the constant risk of failure to remain active, based on the availability of opportunity combined with the intensive effort necessary for performance.
\end{abstract}

Keywords: information tecnology, network, strong tie, weak tie, structural holes 
Este artigo visa realizar uma investigação sobre as configurações de trabalho de profissionais de Tecnologia da Informação, procurando compreender como são estabelecidas suas estratégias individuais de inserção e permanência em um mercado de trabalho cuja organização do processo produtivo configura-se em rede. Iniciamos da conjectura que o setor de tecnologia de informação está, no centro das transformações mais recentes das novas formas de produção, demanda atenção por suas caraterísticas particulares e distintas das configurações de trabalho convencional (Castells, 2007; Boltanski \& Chiapello, 2009; Gorz, 2005; Murteira, 2004).

Esse estudo deriva das reflexões e pesquisas realizadas em tese de doutorado, e contempla uma amostra do campo empírico, uma pesquisa exploratória, de metodologia qualitativa, valendo-se de entrevistas realizadas com profissionais de TI, com vínculos CLT, PJ e sem registro no qual foram observados e identificados padrões de comportamento em níveis hierárquicos diferentes de atuação, buscando caracterizar o trabalho desses profissionais em conformidade com a teoria do Trabalho Complexo (Gorz, 2005) em uma nova configuração do capitalismo (Castells, 2007; Boltanski e Chiapello, 2009; Sennett, 2006), na relação do conhecimento enquanto fator de produção gerador de valor e formação de riqueza (Murteira, 2004) e sob novas formas de troca e de remuneração com distanciamento dos padrões clássicos de medida fundados no trabalho abstrato simples.

Trata-se de estudo qualitativo com utilização de quatro entrevistas semiestruturadas realizadas com profissionais do setor, as quais foram obtidas de uma amostra maior. A pesquisa ocorreu na cidade de Curitiba e Região Metropolitana, Paraná, Brasil. Os quatro participantes possuem formações e estágios de qualificação diferentes, sendo um pós-doutor (Entrevistado 09) com atuação e experiência no exterior, um graduado com título de mestre e experiência de mais de 25 no mercado nacional (Entrevistado 07), um graduando (Entrevistado 08) e um profissional sem formação superior (Entrevistado 03). As análises das falas tomam com referência à Teoria dos Grafos, derivada da Análise Estrutural das Redes Sociais (Lemieux e Ouimet, 2012) e se fundamenta nas observações sobre a constituição dos laços fortes (vínculos de parentesco ou amizade, marcados por ampla troca de informações) e na força dos laços fracos (ligação por conhecimentos, movido por interesses de troca) (Granovetter, 2009), e da articulação das conexões observado a formação e superação de buracos estruturais Burt ( 1992 como citado em Lemieux \& Ouimet, 2012).

Considera-se também, como linha de investigação condutora a verificação do grau de imersão econômica (Granovetter, 2009) que os atores estudados apresentam na formulação de suas estratégias. Os entrevistados são identificados como atores individuais e tomamos como base as relações com seus pares e outros atores coletivos (instituições e organizações). São observados os atributos individuais desses profissionais analisando a forma como são utilizados para superar barreiras burocráticas impostas por organizações e instituições, por meio da mobilização das conexões com outros profissionais na mesma área de atuação, valendo-se de seus laços fracos ou laços fortes (Granovetter, 2009).

Os resultados possibilitaram analisar as configurações das atividades profissionais observando a diversidade de vínculos de trabalho e formas de interação dos profissionais, enquanto atores individuais, nas empresas, 
instituições e organizações. Também foi percebido na estrutura de Rede Social desses profissionais, a exploração dos buracos estruturais (tertius gaudens).

Na escolha dos sujeitos da pesquisa foram eleitos profissionais das áreas de Tecnologia da Informação atuantes nos campos de Desenvolvimento de softwares, Banco de dados e Infraestrutura, considerando também atividades afins relacionadas a consultoria e atendimento ao cliente/usuário, bem como docentes do ensino superior e técnico. Não foi delimitado nenhum tipo de vínculo visando compreender a dinâmica de oferta do trabalho em diversas esferas de atuação, também não foi restrito a um tipo de formação: os profissionais estudados nesta pesquisa variam entre aqueles sem conclusão do ensino médio, com diferencial a partir de certificações ofertadas pelo mercado, independente da instrução formal acadêmica, passando aos graduados, pós-graduados lato-sensu e /ou stricto-sensu.

A hipótese para essa pesquisa considerou os profissionais de TI que, olhando para si próprios, para sua trajetória de experiência, como beneficiários de uma situação de flexibilidade, da diversificação de vínculos e da própria iniciativa empreendedora, operando em Redes, percebem as possibilidades de serem bem e ou mal sucedidos em suas carreiras a partir de suas estratégias de inserção e de permanência no setor e não vislumbram uma estrutura maior e determinante das possibilidades de atuação "ou ação, maior destaque pelas preferência dos que os interesses, o ator não conhece seus interesses e não escolhe a melhor forma de proceder" (Swedberg, 2009, p. 196) que é independente do alcance de suas ações individuais e isoladas.

\section{Teoria dos Grafos: Aspectos Teórico-Metodológicos}

O recorte espacial estabelecido para a realização das entrevistas, no caso a cidade Curitiba, é compreendida aqui como um campo constituído por: (i) suas práticas sociais pré-existentes incluindo a legislação em vigor, as definições de recursos e regras relevantes somadas às habilidades dos atores de explorar tecnologias organizativas, sob a criação de organizações formais; (ii) também caracterizado por regras imersas nas relações de poder entre os grupos formados, constituído por um conhecimento local; e (iii) as estruturas cognitivas utilitárias de quadros culturais voltadas à análise de significados da ação de outros atores (Fligstein, 2009).

A amostra selecionada não permite a criação de um mapa mais amplo, o qual poderia formular uma imagem complexa da Rede de TI na cidade selecionada, mas permite extrair imagens - grafos - de pequeno alcance, cujo foco de investigação volta-se para a ação dos atores individuais e como estes conseguem articular suas relações com os demais, individual e coletivamente. Esse foco específico permite entender como os entrevistados identificam e criam oportunidades para promover suas ações, de que maneira as exploram dentro de suas estratégias de inserção e permanência na rede de atuação.

A visualização dos segmentos de Rede é proporcionada por meio de grafos - que se representações gráficas formada por pontos (vértices) e segmentos de retas ou arcos (arestas) entre eles -demonstrando formas das relações entre os atores sociais e a organização do processo de produção em $\mathrm{TI}$, observadas na realidade local. Nos grafos, os atores sociais representam profissionais, empresas, instituições, organizações e todos aqueles que mantém alguma relação em determinado tempo e espaço, realizando alguma atividade produtiva no setor. 
O objetivo foi demonstrar como esses atores sociais se relacionam e determinam o papel desempenhado pelos profissionais de TI, observando uso do capital social e a utilização de seus conhecimentos específicos da área.

Para descrição e explicação da amostra obtida foi utilizada a metodologia de Análise Estrutural das Redes Sociais (Lemieux e Ouimet, 2012), também conhecida como Teoria dos Grafos (Sperber, 1968). Nessa abordagem os atores, sejam eles individuais ou coletivos, são representados por pontos e suas relações (conexões) são apresentadas na forma de linhas. As linhas aparecem nos grafos de duas formas: como arcos, quando há indicação do sentido expresso por uma linha em forma de seta (flecha) e indica a origem de uma ação; e aresta, quando não há indicação de sentido.

As relações, também chamadas conexões ou laços, apresentam duas características principais: podem ser do tipo orientada, representadas nos grafos por um arco, que é uma seta partindo de um ator para outro e caracteriza quando um ator determina a posição de outro na rede, seja por meio de transferência unilateral de informações, bens ou de serviços ou ação de controle. Ou relações do tipo não orientada, quando há troca recíproca entre os atores e seus atributos e sua representação é dada por uma aresta, uma linha de ligação entre os atores sem indicação de sentido, caracterizando reciprocidade (Lemieux \& Ouimet, 2012).

Os atores podem ser individuais, indicando um profissional de TI, no caso os entrevistados para esta tese e seus colegas de trabalho ou coletivos, quanto representam empresas, instituições ou organizações - uma empresa, por exemplo, é considerada como um ator na Rede e não é explorada sua divisão interna do processo de produção. Segundo Souza (2014), o ator representa um papel dentro de um enredo, em uma trama de relações. Uma classe social pode ser um ator ou mesmo uma instituição e o conceito não está restrito à um indivíduo, podendo ser caracterizado pelo coletivo.

Os grafos visam demonstrar, a partir das conexões entre os atores, os tipos de laços que são estabelecidos, sejam eles fortes ou fracos, e compreender as relações de poder estabelecidas, identificando os posicionamentos mais vulneráveis e compreender como os atores nessas condições formulam suas estratégias de inserção e permanência na Rede. É possível ainda identificar os buracos estruturais, uma outra forma de capital social, mas caracterizada de forma particular em relação ao conceito geral.

Os buracos estruturais se fundamentam numa proposição geral, elaborada por Ronald Burt, na qual um ator "se encontra numa posição vantajosa quando estabelece contatos que não têm qualquer conexão direta entre si" Burt (1992 como citado em Lemieux \& Ouimet, 2012). Condição também conhecida como Tertius Galdens. Condição imprescindível na análise dos segmentos de Rede, pois identifica a posição de um ator e a forma pela qual ele administra as assimetrias de informação entre os demais atores em função das ausências de conexão.

Os segmentos de Rede identificadas consideram que os atores são definidos primeiramente por suas relações e também pela forma dessas relações, com a abordagem do ambiente, suas finalidades, atividades e sua evolução (Lemieux \& Ouimet, 2012). A vantagem da utilização dessa metodologia, consiste em permitir a visualização dos atores em Rede, mas também principalmente possibilitar ampliar ou dar sentido as teses da Sociedade em Rede, identificando como são constituídas as conexões em suas formas mais imediatas, buscando 
responder questões elementares sobre as mudanças nas relações sociais e seus impactos na organização do trabalho nesse modelo de Rede.

Para Lemieux e Ouimet (2012), os laços fortes são constituídos prioritariamente pelas relações mais estreitas entre os atores, no interior da família ou em grupos de pessoas próximas, com tendência a se fecharem mais sobre si. Entretanto os laços fracos aproximam os atores por meio dos "conhecimentos", competências e habilidades, e derivam de ligações com atores individuais mais afastados, ex-colegas de turma ou trabalho, vizinhos não amigos, e sua tendência constituem-se para relações com uma abertura maior (Lemieux \& Ouimet, 2012).

A força do laço fraco é um elemento fundamental em que nós nos apoiamos para interpretação e análise das relações da Rede de profissionais da indústria de software. As relações da Rede se caracterizam pelo lançamento de pontes locais, que integram conjuntos de atores, evitando isolamento, diferenciadas dos laços fortes cuja saturação das informações entre os atores não contribui para avanços exteriores.

Na estrutura da Rede, deparamo-nos com os buracos estruturais que designam uma situação favorável para um ator, cujo posicionamento possibilita intermediação entre outros atores. Isso ocorre quando um ator forma uma ponte entre atores que não se conectam de forma direta. Os buracos estruturais não são possíveis nos grupos constituídos por laços fortes, são predominantes nos grupos constituídos por laços fracos (Lemieux \& Ouimet, 2012).

A vantagem dessa condição, da existência de um buraco estrutural, surge da assimetria de informação entre os atores e subgrupos de atores, aumentando a margem de negociação de um ator que ocupe uma posição intermediária. Essa posição que também pode ser chamada de tertius gaudens, caracteriza uma condição privilegiada no fluxo de informações (Lemieux \& Ouimet, 2012). A visibilidade dessa condição será dada pelos grafos a frente.

Os buracos estruturais podem derivar de situações temporárias e não são exclusivos em função da ausência de contato entre os atores, surgem também em função de hierarquias, em meio a relações de poder entre atores na Rede. Relações de poder e privilégio criam barreiras aos fluxos de informação, os quais podem ser superados por meio de recursos tecnológicos suprimindo algumas distâncias, como destacado por Sennett (2012) sobre o uso de Sistemas Integrados de Manufatura. Podem existir buracos estruturais com base no tipo de conexão, sendo que ela orienta para um ou mais atores, enquanto outro ator pode se beneficiar de atributos de autoridade e posicionamento na Rede.

Assim, a rede constitui um universo de possibilidades ao qual o profissional deve se mostrar promissor, pois, segundo Sennett (2006), a promessa de resultados futuros conta mais do que o histórico passado dos atores observados, sem condição estabelecida, em que todos compartilham o risco da exclusão, e permanecer ativo, qualificando-se de forma permanente, é essencial para atuação. O que reafirmam o conceito de rede fornecido por Castells caracterizando como:

[...] instrumentos para a economia capitalista baseada na inovação, globalização e concentração descentralizada; para o trabalho, trabalhadores e empresas voltadas para a flexibilidade e adaptabilidade; 
para uma cultura de desconstrução e reconstrução contínuas; para uma política destinada ao processamento instantâneo de novos valores e humores públicos; e para uma organização social que vise a suplantação do espaço e invalidação do tempo. Mas a morfologia da rede também é uma fonte de drástica reorganização das relações de poder (Castells, 2007, p. 498).

Na estrutura interna da Rede de profissionais as relações se dão pelas composições dos projetos contratados. É a ponte entre os profissionais e justamente o conhecimento específico necessário para o desenvolvimento de cada projeto, no caso da criação de software, correspondem as duas principais atividades, a de programação, compreendendo a execução das tarefas predefinidas, e a de análise, elaborando as soluções necessárias e constituindo as etapas de planejamento.

\section{O Funcionamento da Rede dos Profissionais em TI: Resultados do Campo Encontrados em Curitiba e Região}

\section{Metropolitana}

A estrutura de rede não é um processo exclusivo da TI, pois é caracterizada pela cooperação que pode existir em diversas áreas, sob diferentes formas, seja na perspectiva do cooperativismo, seja limitada a uma combinação de esforços entre diversos atores, caracterizados por indivíduos, empresas ou organizações. No caso dos profissionais de $\mathrm{TI}$, eles também se articulam em rede, e sua estrutura expressa elementos específicos que a torna complexa.

As questões que dão direcionamento a nossa análise estão relacionadas aos casos de sucesso dos profissionais, aos momentos de fracasso, a adrenalina no exercício da atividade, a pressão por resultados, as dificuldades para obter estabilidade, a realização de consultorias e noções de empreendedorismo.

O trabalho realizado é complexo, da ordem do imaterial (Gorz, 2005), sendo os limites de sua execução não passíveis de serem testados, portanto, as metas e prazos ganham ênfase em sua subjetividade. A frase que marca a rotina desses profissionais é uma constante: apagar incêndios, sempre há mais a ser feito diante de situações emergenciais e prazos estreitos, difíceis de serem definidos com precisão.

As consultorias aparecem como formas de superação das pressões estruturais, são as oportunidades de vender o produto ou realizar o serviço em outra etapa da carreira profissional, quando a disposição para atividades de cunho operacional se torna desmotivadora e desgastante. A consultoria associa-se a um sentimento de empreendedorismo, não sob a forma de um discurso, pois este não é manifestado pelos entrevistados, apenas identificado em um conjunto de crenças e valores evidenciados por comportamentos similares.

Com base nos elementos acima elencados passamos a dar destaque aos tipos de conexões que produzem efeitos na rede de trabalho, aquelas que permitem as interações em diversos níveis de atividades e que parecem não transparecer modelos hierárquicos de disposição e de controle. A começar pela identificação dos laços forte e laços fracos, seguido da análise sobre os buracos estruturais, por conseguinte os fluxos incessantes e como e por fim impactou nas condições objetivas de trabalho.

Identificamos entre os atores que constituem a estrutura da Rede dos profissionais da indústria de software, as condutas do Redeiro e a do Integrador de Redes. A primeira é pautada por ações negativas e 
individualistas, visa tirar proveito da assimetria de informação gerada pelos buracos estruturais entre os atores, ou seja, a figura do oportunista. Já o integrador de Rede trabalha para superar as assimetrias de informação e proporcionar maior integração entre os profissionais. Ambos procuram o sucesso, diferenciando-se pelo fato do primeiro obter bons resultados isoladamente, enquanto o segundo visa alcançar um bem comum (Boltanski \& Chiapello, 2009).

Os participantes das entrevistas selecionadas não são colegas em uma mesma empresa e não estevam envolvidos no mesmo projeto na ocasião da coleta de dados. A abordagem da entrevista levou em consideração suas formas de manter contatos tanto para oferta de suas especialidades, quanto na relação com a especialidade de outros profissionais. Da amostra selecionada foi possível identificar a existência dos laços fracos e fortes (Granovetter, 2009), buracos estruturais Burt (1992 como citado em Lemieux e Ouimet, 2012) e identificar assimetrias de informação e identificar as condutas de Redeiro e de Integrador de Redes.

Os entrevistados selecionados para a amostra apresentam situações das quais se beneficiaram por meio das cadeias relacionais curtas, dos laços fortes caracterizados pelos vínculos de parentesco ou amizade. Entretanto, as análises contidas nesse tópico dão destaque aos laços do segundo tipo, fundamentando-se na teoria desenvolvida por Granovetter (2009 como citado em Lemieux \& Ouimet, 2012). Para Granovetter (2009), os laços fracos possuem uma força mais significativa em relação aos laços fortes, constituindo cadeias relacionais longas, (Lallement, 2004), as cadeias relacionais curtas, ou em outras palavras os círculos familiares e de amizade, são menos eficientes no êxito dos atores que buscam uma colocação, o que não significa dizer que são irrelevantes para as formas de ingresso no mercado de trabalho.

Essa percepção de importância das cadeias relacionais curtas é observada também pelo Professor e Acionista (E9) que, após ser questionado sobre a relevância dos atributos pessoais de um profissional em relação ao grau de proximidade que este possa ter com outros atores - por meio dos laços fortes, para preenchimento de uma vaga de trabalho - considerou a partir de sua experiência que as contratações têm maior frequência a partir dos laços fortes:

[...] eu posso estar errado, mas na minha perspectiva é algo muito pessoal. Eu já vi casos que era mais de conhecer a pessoa, “[...] o cara é legal [...], vou arrumar um emprego para ele, vou fazer ele trabalhar aqui nesse período" [...]. Eu acho que isso acontece bastante em TI, eu já vi bastante, "o cara é muito gente boa, dá um jeito pra ele". E eu acho que acontece mais nesse sentido do que pela competência [...]. A impressão que eu tenho, pela competência, o cara que é muito bom naquilo que ele faz, ele está empregado e ele depende muito pouco dessa Rede [laços fortes] de contatos para se recolocar de volta no mercado (Entrevista 09: Professor e Acionista, Bacharel em Informática, 46 anos, casado)

O relato do Professor e Acionista (E9) comporta a interpretação dos dois tipos de laços existentes. Atribui frequência maior para ocorrências relacionadas aos laços fortes, mas destaca, de forma indireta, nesse tipo de situação uma superação da insuficiência das competências, ou ausências de conhecimentos específicos ou relevantes para entrada em um projeto ou ocupação de vaga com base em critérios de confiança, em conformidade 
com o conceito de imersão em Granovetter (2009). Logo em seguida, destaca que o conhecimento e a reputação do profissional, quando esses atributos o precedem, colocam-no numa situação em que as cadeias relacionais curtas podem ser dispensadas - o mercado encontra o profissional sem que este dependa dos laços fortes.

O Gerente de TI e Infraestrutura, CLT, 44 anos (E8), dentro da mesma linha de raciocínio, contribui para essa visão sobre os laços fortes quando diz:

[...] quando o 'cara' é bom, não interessa o que ele tem, não precisa ter título nenhum. O 'cara' vai se dar bem ou vai entrar [na área], [...] vão correr atrás dele, porque ele é bom. [...] ele se segura por si mesmo. [...] quando eu digo bom, é bom mesmo, tanto que o pessoal sempre fala - Onde que eu ouvi isso? Foi o Steve Jobs que falou - o cara que é bom vale no mínimo por 10 normais. E não estamos falando dos caras ruins, normais - aquele cara que faz direitinho o serviço e tal. Ele [o bom] vale no mínimo por 10 normais. Então é alguém que se destaca mesmo. Estilo o Marcelo Tosatti, com 14 anos! Você olha, o cara é um gênio, entendeu? (Entrevista 08: Gerente de TI e Infraestrutura, Bacharel em Informática, 44 anos, casado)

A explanação feita pelo entrevistado estima que os conhecimentos e potenciais dos profissionais vão além, ou independem, do círculo familiar ou de amizades para uma colocação e definição de um posicionamento na Rede. Os atributos dos profissionais os destacam pelo potencial de realizações em um segmento específico.

A referência que o Gerente de TI e Infraestrutura, CLT, 44 anos (E8) faz ao nome de Marcelo Tosatti reporta a um caso emblemático em Curitiba, quando este, enquanto programador, iniciou suas atividades aos 14 anos de idade, recebeu, ainda aos 19 anos, o convite de Linus Torvalds para se tornar mantenedor de uma das versões do sistema Linux (versão 2.4.), considerado o nível mais elevado, em escala global, de privilégio para um programador desse sistema operacional.

Embora o caso acima esteja dentro de uma situação particular e, característica do setor nesse segmento para a época, o episódio chama atenção pelo alcance da Rede e superação de barreiras de diversos tipos, a começar pela superação territorial, a formação acadêmica e a proximidade pessoal com outros membros da Rede: o principal desenvolvedor, e criador, de um sistema utilizado em escala global, com sede nos E.U.A., por meio de uma empresa local na cidade Curitiba, no estado do Paraná, Brasil, efetiva a contratação de alguém que vem a ser seu principal programador. Não há nessa situação, nenhuma relação de parentesco ou de amizade que venha a ser relevante no posicionamento dos atores envolvidos. O laço fraco é estabelecido em função da articulação de conhecimentos existentes, nele é explorado o potencial para transformações e novas realizações. Nos chama a atenção em função do objeto de estudo na configuração de trabalho dos entrevistados para a pesquisa, esse fenômeno específico destaca uma característica encontrada na ponta da rede, a de localizar e tornar acessível todo e qualquer recurso. Entretanto, as considerações sobre os laços fortes, que possam existir nos segmentos de Rede analisados, não são desconsiderados e fazem contraponto na interpretação de situações em que o conhecimento, enquanto fator de produção, não é o principal atributo de distinção no posicionamento de um ator.

Ainda sobre o alcance global que o conhecimento produzido localmente pode ter, e de como este pode transpor barreiras por meio dos atributos pessoais do ator, retomamos a entrevista realizada com o Professor 
e Acionista (E9), cuja atividade de pesquisa o coloca num panorama de demanda internacional por seus conhecimentos. Ainda que perceba uma maior entrada e recolocação de profissionais no mercado por meio dos laços fortes, o profissional, hoje não depende desse tipo de cadeia relacional curta, posto que o alcance de suas publicações desperta a atenção de outras localidades fora do território nacional, como ele explica:

Então, eu tenho um monte de artigo publicado. Esses tempos uns caras do Chile - que eu tenho projeto com eles até hoje por causa disso - me mandaram um e-mail falando: "você não está a fim de dar umas consultorias para nós? Nós lemos os teus artigos e estamos implementando aqui. É tudo o que estamos lendo", [...]. Então beleza, não preciso sair da universidade, a rede de contato nesse caso ela faz uma interface que seria pela publicação científica.

Além das publicações que permitem que o conhecimento compartilhado anteceda o contato consequente, o Professor e Acionista organiza encontros internacionais que visam a proliferação de avanços científicos na área. Os eventos acontecem anualmente e contam com parcerias com universidades do Canadá, França, Chile e outros países. Essas parecerias permitem uma atualização de conhecimentos permanentes e troca de informações importantes entre os atores individuais e coletivos.

Em concordância teórica, Boltanski e Chiapello (2009) apresentam formulação sobre a relação dos laços fortes e laços fracos, onde as atribuições, em função da existência de barreiras institucionais, só podem ser transpostas por atores específicos, cujas posições consolidadas são insubstituíveis por outros integrantes da Rede. Como pudemos observar no caso anterior, não somente a publicação dos artigos deram alcance ao conhecimento produzido localmente, mas a condição de autoridade acadêmica respaldada por uma instituição centenária atesta que um ator individual está divulgando. Situação que é possível observar a partir da experiência de mais de 10 anos do Analistas de Sistemas e Consultor em Segurança, PJ, 39 anos (E3) na sua relação com seu principal empregador, um perito na área de segurança, mas que não dispõe dos conhecimentos informacionais sobre sistemas operacionais e suas falhas de segurança. O Analista de Sistemas e Consultor em Segurança (E3) não pode transpor as barreiras que seu principal empregador já superou. O conhecimento de que dispõe somente pode ser aplicado por meio de uma ponte entre ele e o cliente final, o que leva a seguinte interpretação de sua situação:

Mas eu prefiro manter uma questão assim, fidelidade. Porque eu sei que na hora que eu preciso, nesse mercado de segurança, o [FULANO] consegue me ajudar, ele consegue inserir eu lá dentro do Palácio do Governo, em que ele tem muito contato. Do que eu trabalhar sozinho. (Entrevista 03: Analista de Sistemas e consultor em Segurança, graduando em Sistemas de Informação, 39 anos, casado)

Esse relato dá um indicativo do tipo de barreira que não pode ser superada pela simples ocupação de uma posição. A posição de um ator é sustentada por atributos específicos e constitui outra rede de atuação, sendo o trabalho de consultoria uma das facetas do trabalho realizado pelo seu contratante.

Voltando para as questões das conexões para além dos laços fortes e fracos, a estrutura de Rede de profissionais também apresenta elementos que identificam laços adormecidos, fluxos incessantes e buracos estruturais. Os laços adormecidos constituem conexões potenciais, que podem ser acionadas a qualquer momento 
em conformidade com o mercado e sua demanda por conhecimento. Os fluxos incessantes somente atingem resultados significativos quando canalizados por projetos, sistema de organização da força produtiva. Os buracos estruturais proporcionam posicionamentos vantajosos aos atores na rede.

Uma das características da estrutura das Redes Sociais é sua impossibilidade de mapeamento pleno. Mesmo a Rede de profissionais de TI, se fosse definida como meta para tal objetivo, não se mostraria de fácil apropriação, ou pelo número de atores pertencentes ou o número de suas ligações, posto que a cada etapa de seu desenvolvimento em uma linha temporal, ou avanço cronológico, não corresponderia mais ao mesmo retrato obtido no momento anterior. Conforme visto anteriormente, os atores que se encontram momentaneamente fora da rede não apareceriam em um mapa elaborado, o que ocorreria em função de ausência de conexões, seu retorno às atividades pode ser uma questão de tempo ou mesmo não acontecer, ocasionado por uma situação de insucesso temporário ou permanente.

Ao analisarmos alguns extratos da Rede de profissionais da indústria de software em Curitiba e Região Metropolitana foi possível identificar alguns buracos estruturais. São lacunas existentes entre as grandes empresas e um determinado grupo de profissionais (programadores ou analistas), como será possível observar na Figura 1, abaixo:

\section{Figura 1}

Representação das relações orientadas entre oito atores e formação de buraco estrutura pelo entrevistado 07 entre empresa multinacional (em) e seis programadores (P1-P6)

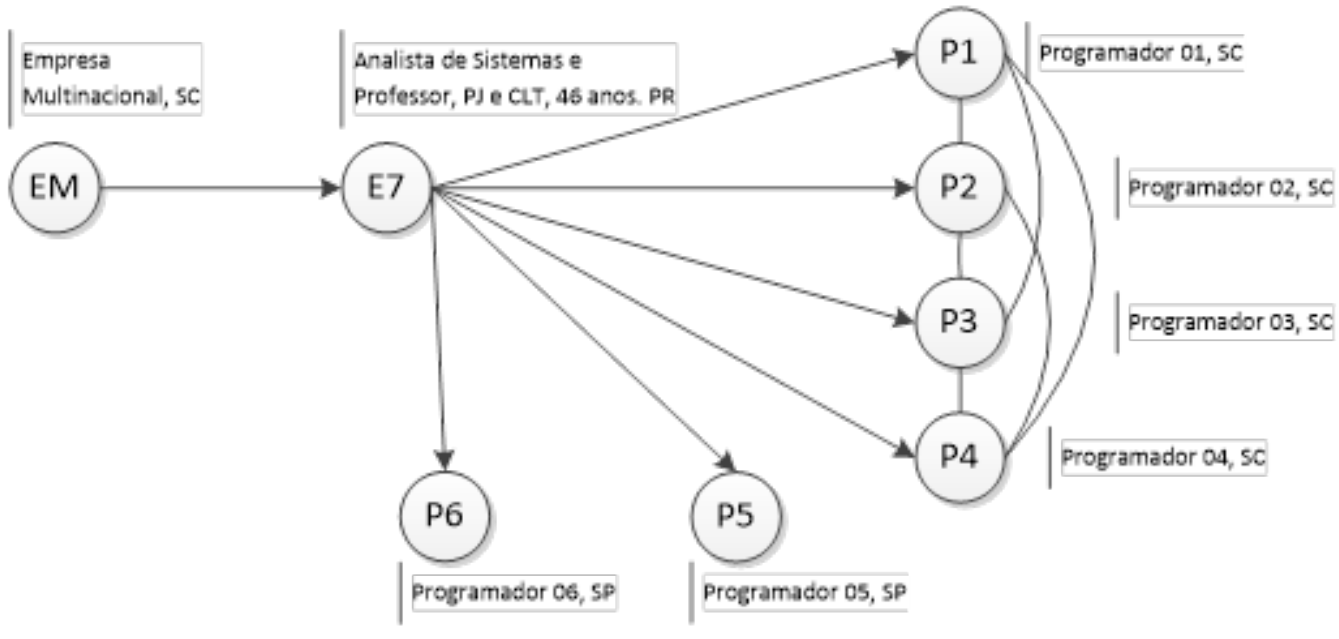

Nota: Elaborada pelo autor (Pesquisa de campo, 2012-2015).

A Figura 1 foi construída a partir da entrevista realizada com o Analista de Sistemas e Professor (E7), e demostra a relação entre 8 (oito) atores sociais, constituída por seis programadores, um analista de sistemas e uma empresa multinacional (EM).

São apresentadas 7 (sete) relações orientadas - identificadas como setas na figura, demonstrando de qual ator parte a ação) em que a Empresa Multinacional (EM) é a fonte do Analista de Sistemas e Professor, CLT e PJ, 46 anos (E7), que por sua vez é a fonte intermediária de outros 6 (seis) programadores (P1 - P6). Os programadores representados no grafo são alvos e encontram-se no final de uma conexão de comprimento 2 - que designa o alcance da ação entre os atores fonte e os atores alvo - para o segmento de rede analisado. Os programadores P1, 
P2, P3 e P6 formam um subgrupo, cuja subordinação está ligada ao Analista de Sistemas e Professor (E7). Os outros dois programadores, P5 e P6, são apenas subordinados - não se confirmou que houvesse troca de informação entre os programadores de São Paulo entre si e com o subgrupo formado no estado de Santa Catarina.

Ainda sobre o conjunto de programadores, aqueles que residem no estado de Santa Catarina, eles mantêm uma coesão e esta condição não os favorece em termos de alcance de suas ações, posto que dependem hierarquicamente das demandas do Analista de Sistemas e Professor (E7). Suas relações são caracterizadas por redundância nos contatos (laços fortes) e estão a par dos mesmos benefícios. Esta é uma condição ao menos em relação a E7, posto que todos os atores na rede podem manter e criar conexões com outros atores que não aparecem no extrato de rede acima identificado. $\mathrm{O}$ imbricamento entre formal e informal tornam borradas as fronteiras das atividades que um profissional do setor pode executar, e com quantos outros atores podem se relacionar na Rede.

A empresa contratante do Analista de Sistemas e Professor, CLT e PJ, 46 anos (E7), utiliza no seu processo de fabricação uma linha de produção automatizada, compreendendo desde a entrada do insumo in natura até a saída do produto industrializado, embalado e pronto para o consumo (atendimento nacional e exportação). Sua linha de produção é constituída por diversos equipamentos, de diferentes fabricantes e operados por softwares específicos e distintos. A necessidade da empresa contratante está em desenvolver um terceiro software de comunicação para essas máquinas, visando a integração delas à linha de produção. Ou seja, o tipo de projeto que o Analista de Sistemas e Professor, CLT e PJ, 46 anos (E7), gerencia é a elaboração de softwares de interfaceamento.

Nesse caso, o buraco estrutural é identificado pela ausência de conexão entre a Empresa Multinacional (EM) e outros 6 (seis) programadores. O Analista de Sistemas e Professor (E7) ocupa uma função intermediária, também chamada de Tertius Gaudens. É a partir dessa condição que ele organiza a produção e se vale da força de trabalho disponível para execução dos projetos. Nessa verificação, o Analista de Sistemas e Professor (E7) desempenha o papel semelhante ao de Redeiro Oportunista, aquele que:

[...] tira proveito de um diferencial de mobilidade em relação a atores que, por diferentes razões (morais, familiares, institucionais, patrimoniais etc.), permanecem ligados a um lugar, atores cuja confiança ele conseguiu granjear (quer se trate de colaboradores próximos, de mandantes dos quais ele dependa institucionalmente, quer de pessoas afastadas, com as quais ele consiga conectar-se) (Boltanski \& Chiapello, 2009, p. 389).

O ator intermediário, para o caso em questão, usa sua posição para controlar o fluxo de informação e demanda de serviços, mas também pode controlar a entrada de novos atores. Assumir a demanda integral da Empresa Multinacional (EM) foi uma estratégia adotada, como vemos em seguida. O Analista de Sistemas e Professor (E7) buscou administrar todo o segmento de rede que deriva de sua posição a fim de evitar a entrada de novos concorrentes, cabendo a ele a organização da força de trabalho disponível.

A partir da fala do Analista de Sistemas e Professor (E7) foi possível identificar um buraco estrutural em sua condição de terceirizado para prestação de serviços informacionais a uma empresa de grande porte, produtora 
nacional e internacional de alimentos industrializados. Ele expõe como articula seus contatos, subconjunto de programadores contratados como PJ, para atendimento da demanda da contratante fonte Empresa Multinacional (EM):

[...] a contratação de outros profissionais, o que acontece? Tem uma demanda sazonal, as vezes eles [Empresa Multinacional EM] tem 7 ou 8 projetos com prazos de implantação de poucos dias, poucas semanas, até muito mais do que eu consigo fazer. Então aí, para não perder esses projetos, o meu pensamento é assim: se eu digo que não vou ter condições de atender, eles vão cadastrar, vão mapear outros [profissionais] que poderão fazer [...], que vão ser meus concorrentes [...]. Então eu prefiro eu mapear esses outros camaradas e eles prestam serviços para mim. Então eu 'quarteirizo' [sic] esse serviço.

(Entrevista 07: Analista de Sistemas e Professor, Bacharel em Processamento de Dados, 46 anos, casado) A Empresa Multinacional (EM) do Analista de Sistemas e Professor (E7), caracteriza-se como uma fonte e mantém com ele uma relação orientada (relação assimétrica), por meio de um contato direto para suprir uma demanda sazonal de projetos para desenvolvimento de softwares específicos. Esses softwares servem para a integração do parque industrial de máquinas, na unidade de produção no estado de Santa Catarina, BR.

O que caracteriza a relação entre EM e E7 como orientada é sua assimetria de informação. O Analista de Sistemas e Professor (E7) não possui informações suficientes sobre as decisões de Empresa Multinacional (EM) e não tem como saber sobre a continuidade da demanda por projetos existentes. Hipoteticamente, a Empresa Multinacional pode encerrar suas atividades, pode redirecionar sua demanda por softwares para outros atores (profissionais e/ou empresas concorrentes de E7) ou mesmo não depender desse tipo de processo - a terceirização da fabricação de software - para manter sua linha de produção em funcionamento. O Analista de Sistemas e Professor (E7) considera essas hipóteses ao organizar sua rede de contatos e dimensionar sua oferta de serviços. Ao ser questionado sobre a insegurança de sua atividade nesse segmento, responde que é "altíssima" e justificada:

[...] Porque eu estou trabalhando com um nicho extremamente específico, e a tendência é que as próprias empresas [fornecedoras de equipamentos / máquinas] assumam essa atividade. Quer dizer, eu vou te entregar um equipamento e perguntar qual é teu parque de máquinas, eu já tenho o driver de comunicação para tua máquina. Isso aqui já está comum e em atividade. O volume de serviço que eu tinha quando eu comecei com a Empresa Contratante EC em relação a agora diminuiu significativamente. [...] mas isso está diminuindo e eu sei que isso, mais cedo ou mais tarde, zera. (Entrevista 07: Analista de Sistemas e Professor, Bacharel em Processamento de Dados, 46 anos, casado)

A flexibilidade nessa situação é importante em função do constante risco de encerramento das atividades. É preciso estar preparado para encerrar as atividades e desmobilizar essa estrutura - o segmento de rede que compõe o subgrupo de programadores -, circunstância que levou o Analista de Sistemas e Professor, a promover alteração nas relações de trabalho que tinha com dois de seus programadores: "[...] então eu tinha funcionários registrados, CLT, o último demiti hoje. Fiz a rescisão hoje e passaram todos a ser terceirizados". (Entrevista 07: Analista de Sistemas e Professor, Bacharel em Processamento de Dados, 46 anos, casado) 
O Analista de Sistemas e Professor (E7) caracteriza-se como alvo, e também como contato, da Empresa Multinacional (EM) assumindo a demanda de forma incondicional com o objetivo de não permitir a entrada de novos prestadores de serviços, analistas e programadores concorrentes. Desta forma, ele busca evitar a ampliação da Rede de contatos de Empresa Multinacional, o que gera uma necessidade de ampliar e administrar os contatos descendentes a partir da sua condição de intermediário, conforme depoimento abaixo.

Os [programadores] de SP, surgiram no processo em uma época em que estava com muita demanda e precisava cumprir prazo. Depois, os mantive em outros projetos para não perder o contato. Eles contribuíram muito na moral do grupo. Embora não se conhecessem todos sabiam que os outros existiam. (Entrevista 07: Analista de Sistemas e Professor, Bacharel em Processamento de Dados, 46 anos, casado) Esse profissional se vale de um subconjunto de contatos constituído por programadores, estabelecendo relações orientadas, a partir da cidade de Curitiba. A demanda por serviços que mantém para esses programadores, e o compartilhamento de algumas informações sobre a distribuição dos projetos, sustenta sua posição favorável e assegura o atendimento de seu único cliente nesse segmento, a Empresa Multinacional (EM).

A exemplo do Analista de Sistemas e Professor, que ocupa função de intermediário na Rede, quando se parece possível atribuir uma conduta de Redeiro, de alguém que explora uma oportunidade por meio da assimetria de informação, ficamos na dúvida sobre seu verdadeiro papel. Se ele não seria um Integrador de Rede, posto que suas ações, mesmo que revertidas em vantagens por seu posicionamento intermediário, garante resultados proveitosos para os demais atores (Boltanski e Chiapello, 2009), levando soluções para a empresa contratante, Empresa Multinacional (EC) e assegurando vagas e remuneração para outros 6 (seis) programadores.

Sob a perspectiva do integrador de Redes, o Analista de Sistemas e Professor (E7) mobiliza a força de trabalho necessária para o atendimento da Empresa Multinacional (EM). A pressão que E7 recebe de EM o obriga ampliar sua rede de contatos subordinados e também manter sua continuidade, pois não se pode supor que uma empresa de porte nacional e internacional seja refém numa relação, ou mesmo que não possa abrir novas conexões, mantendo apenas um único contato para atendimento de suas demandas por softwares. 0 suposto Redeiro então fica como o responsável por reduzir custos de produção, gerenciar todo um segmento de profissionais, administrar os prazos estipulados e ainda definir a precificação dos produtos e os salários do subgrupo. O pagamento para todos esses serviços está implícito no preço do projeto, a contabilidade posterior a entrega do produto para definição da remuneração das atividades ao subgrupo cabe ao ator intermediário (Entrevista 07, Analista de Sistemas e Professor).

Se a condição de intermediação não for preenchida pelo Professor e Analista de Sistemas, ou mesmo deixar de existir, não só sua situação é findada como também daqueles que ele gerencia - se aqueles não buscarem novas conexões ou superarem a condição do intermediário. A flexibilidade nesse caso faz com que o profissional não aposte numa única fonte, devendo transitar permanentemente entre diversas oportunidades.

Outro buraco estrutural identificado a partir das entrevistas realizadas foi partir da posição isolada do Analista de Sistemas e Consultor de Segurança, PJ, 39 anos (E3). Diferente do arranjo apresentado no caso anterior, 
a condição de vantagem não se vale de uma posição intermediária para obter resultados satisfatórios do trabalho que realiza, mas evidencia outra estratégia de atuação que também favorece o profissional - ao menos em sua perspectiva de atuação e dos recursos que dispõe para atuar na Rede. O caso trata de um profissional qualificado, com certificações por empresas especializadas na área de segurança de softwares, mas que ainda não possui título de graduação na área de atuação. Esse profissional atribuiu a uma de suas conexões a possibilidade de colocar em prática seus conhecimentos e potencialidades sob a seguinte lógica:

[...] você vai montar uma empresa, você tem que sacar o seguinte: você tem que se apegar com uma empresa que tem know-how no mercado, não para você se aproveitar da situação, porque eu acho que você acaba queimando o seu filme. (Entrevista 03: Analista de Sistemas e consultor em Segurança, graduando em Sistemas de Informação, 39 anos, casado)

O Analista de Sistemas e Consultor em Segurança, PJ, 39 anos (E3) atua como Pessoa Jurídica e tem quase exclusivamente um único cliente, o Contratante E3. Ele aposta na conexão com esse ator em determinado segmento da Rede, em um mercado específico do setor, o de segurança de informação, com desdobramento para segurança de software, entendendo, pois, que o alcance de suas próprias ações, sem essa conexão, seria limitado, dado seus atributos pessoais e em função de seu capital social.

A Figura 2 apresenta a visualização do segmento de rede extraído a partir da fala do Analista de Sistemas e Consultor de Segurança (E3). Nele são identificados para fins de análise cinco atores sendo quatro individuais e um coletivo que é representado pelo Governo do estado do Paraná, no ano de 2013. Acompanhamos o Figura 2 em sua configuração a partir do posicionamento dos atores:

\section{Figura 2}

Representação das relações orientadas entre seis atores e formação de buraco estrutural pelo empregado E3 entre clientes $C 1$, C2 e CN E O entrevistado E3

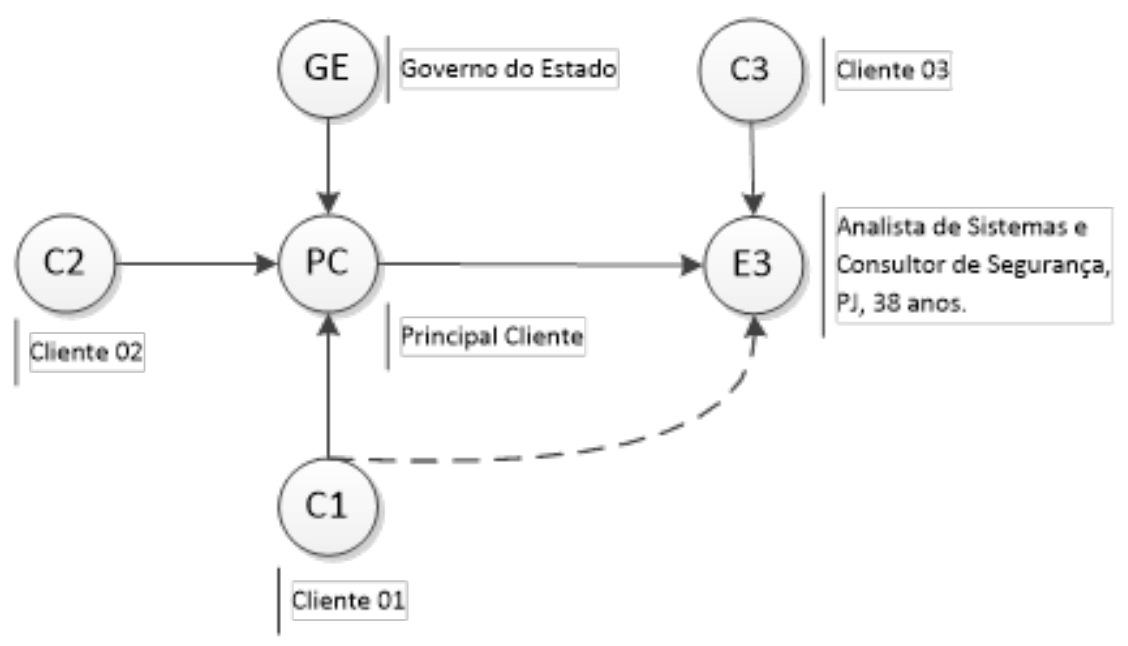

Nota: Elaborada pelo autor (Pesquisa de campo, 2012-2015).

São apresentadas 6 (seis) relações orientadas, sendo 3 (três) dos atores fontes C1, C2 e GE para o contato PC, que por sua vez mantém uma relação orientada com E3. O Analista de Sistemas e Consultor em Segurança (E3) também recebe outras duas ligações orientadas, uma positiva da fonte C3 e uma negativa a partir da fonte C1. 
O que caracteriza a relação orientada de C1 para E3 como negativa é a tentativa do ator fonte Cliente 03 (C3) de saltar o buraco estrutural existente e preenchido pelo Principal Cliente (PC). O objetivo de C1 é encurtar o caminho e converter E3 em um contato direto, possivelmente para reduzir custos na transação obtendo vantagens diretas, eliminado a ponte existente entre os dois.

Mesmo quando surgiu a proposta de cortar o caminho e criar uma conexão direta por meio de proposta de um cliente do contratante PC, o Analista de Sistemas e Consultor em Segurança (E3), recusou e denunciou a ocorrência:

Por exemplo, assim, eu já recebi proposta trabalhando com o Principal Cliente (PC), e dizerem [C1, cliente de PC] "você não quer fazer em separado?", e eu como tenho muita fidelidade com ele, não é por uma questão de amizade, de eu chegar para ele e dizer "teu cliente solicitou que eu fizesse um trabalho", ele [PC] dá risada as vezes, ele fala o seguinte "o cara é sacana de fazer isso". Então eu mostro para ele o seguinte que tem que ter essa confiança, então não é assim, porque para você se sujar nesse mercado nosso é fácil. (Entrevista 03: Analista de Sistemas e consultor em Segurança, graduando em Sistemas de Informação, 39 anos, casado)

Os Analistas de Sistemas e Consultor em Segurança, PJ, 39 anos (E3) busca manter a integridade de sua conexão evitando criar situações que desfavoreçam seu principal cliente, Contratante EC, impedindo que haja assimetria de informação - ao menos no que diz respeito a sua posição. Mas é preciso ressaltar que não há evidência contida nessa ou em outra fala que demonstre tal reciprocidade, de que seu contratante (PC) não considere a possibilidade de novas contratações. A aposta é unilateral pela confiança de E3. Como o Analistas de Sistemas e Consultor em Segurança (E3) destaca em sua fala, "não é por uma questão de amizade" (laço forte), destacando como valor e conduta adotada de relatar a proposta recebida, ação relativa a especificidade do mercado com foco na ampliação do alcance de suas ações e permanência nesse segmento. E3 atua como um Integrador de Redes, enquanto seu Principal Cliente (PC) cumpre um papel de Redeiro Oportunista. Podemos dizer que nesse caso, a fidelidade é uma estratégia para manter e criar uma relação de confiança, e o entrevistado reconhece que suas relações estão mantidas por meio do conhecimento específico (laços fracos) e demandado por um segmento de mercado. Não respeitar a relação de confiança é colocar em risco a permanência no segmento de atuação.

Podemos observar que a confiança estabelecida entre o profissional e a empresa contratante é uma forma de assegurar a permanência na Rede. No relato anterior, o entrevistado expõe a possibilidade de ampliar sua Rede estabelecendo novos vínculos, burlando as relações e traindo a confiança com seu principal contratante (Redeiro). A possibilidade de receita imediata para o Analista de Sistemas e Consultor em Segurança, PJ, 39 anos (E3) teve menos relevância em sua escolha do que a integridade do vínculo a ser mantido. O know-how da empresa com a qual mantém um laço fraco, e que busca tornar exclusivo, está associado à sua estratégia de permanência, evitando se sujar no mercado. A recusa na criação de contatos diretos, fazendo desses clientes efetivos para a empresa contratante, fortalece o laço fraco e diminui o risco de exclusão. 
É importante destacar que o posicionamento de PC é uma condição que não pode ser assumida pelo Analistas de Sistemas e Consultor em Segurança (E3) dado seus atributos: formação, conhecimentos e Rede de contato pré-existente. Sem o contratante PC, E3 fica restrito, mesmo com possibilidade de maior remuneração para um cliente direto (C1) por serviços prestados, o risco é maior.

O Analistas de Sistemas e Consultor em Segurança (E3) apresenta em sua narrativa as características do Integrador de Redes, mantendo uma conduta de interesse na ampliação das suas oportunidades de trabalho por meio de seu Principal Cliente. O Analistas de Sistemas e Consultor em Segurança, PJ, 39 anos (E3) dá prioridade a um de seus contratantes a partir de sua visão da Rede e suas possibilidades, mas o faz beneficiando seu Principal Cliente. Por sua vez, também apresenta as características do Redeiro:

[...] ele não comenta, mas ele sabe que se ele falar assim: "preciso de você as 05:00 da manhã lá no aeroporto, por que nós precisamos viajar e ficar três dias em São Paulo", eu não falo não para ele. Porque o único cara que ele tem para contar hoje sou eu. Então porque para ele é prático e se ele falar "Paulo, se você não quer fazer eu vou contratar outra empresa". Ele faz assim com a mão [simula um estalo com os dedos], cai uma [empresa] na hora. E ele é um cliente fiel para mim, porque é o maior e o melhor cliente que eu tenho hoje. Então ele sempre está me apresentado para gente que é conhecida aí fora [...] então é legal trabalhar com um cara que é conhecido no mercado. (Entrevista 03: Analista de Sistemas e consultor em Segurança, graduando em Sistemas de Informação, 39 anos, casado)

Podemos observar a partir das falas do entrevistado 03, quando na condição de integrador de Redes justifica sua ação com a fidelidade a um Redeiro. Observa-se nesta fala a percepção da estrutura de Rede na qual se pretende estar inserido, justificando fidelidade à empresa na qual se presta serviços. Ao se referir ao presidente da empresa, comenta:

[...] eu estando com ele, eu estou atendendo o Brasil inteiro, eu sozinho não conseguiria atender ao Brasil inteiro, porque ele tem uma infraestrutura e uma Rede de contatos muito boa, ele tem muitos contatos e viaja muito para fora. Então eu vejo assim, que essa área nossa, de segurança de $\mathrm{TI}$, a questão hoje é network, fazer contato. (Entrevista 03: Analista de Sistemas e consultor em Segurança, graduando em Sistemas de Informação, 39 anos, casado)

Verificamos que este profissional reduz sua gama de contatos apostando na força do laço fraco que mantém com um empresário no ramo de consultoria no setor de segurança. Sua estratégia e visão de negócio se fundamenta na percepção das barreiras institucionais, as quais sente que não pode transpor sem a vinculação com a conexão à qual atribui mais força. O entrevistado possui um laço fraco com a empresa, na figura de seu presidente e pressupõe, ou percebe, que sua ação isolada não tem alcance relevante se for fundamentada apenas em sua capacidade técnica. O presidente da empresa, por sua vez, está envolvido em uma quantidade significativa de buracos estruturais, o que privilegia a oferecer os serviços técnicos do Analistas de Sistemas e Consultor em Segurança, PJ, 39 anos (E3). 
É justamente a noção de risco do Analistas de Sistemas e Consultor em Segurança (E4) que o faz querer transferir outros contatos de sua Rede para EC, visando ampliar ainda mais a força do laço fraco existente, ampliando assim a confiança entre os atores.

Tenho uma flexibilidade, [...] por exemplo: eu tenho uma outra empresa que atendo, que é minha [C3], [...] na época eu ofereci para ele $[\mathrm{EC}]$ e ele me disse "mantenha o cliente para você, a gente vai fazendo daqui para frente" [época do início da relação]. Só que eu não misturo, cliente meu, por exemplo, o contrato que eu tenho com ele é: se eu precisar atende-lo, eu atendo ele no sábado - já estipulei com ele. Quando eu estou atendendo o meu cliente [C3] aqui, em momento algum eu deixo ou misturo as coisas. Então a gente tem uma flexibilidade muito boa e é uma questão de confiança. Por que eu sei que se eu aprontar com ele eu vou me queimar no mercado. E se um cara na área de TI queimar o filme dele, esqueça. (Entrevista 03: Analista de Sistemas e consultor em Segurança, graduando em Sistemas de Informação, 39 anos, casado) Novamente, o relato traz à cena a importância de confiança para os que participam da Rede. É assim que o Analista de Sistemas e Consultor em Segurança (E3), na condição de Pessoa Jurídica, tem a possibilidade de realizar outros trabalhos para outras empresas, como ele destaca em sua fala, há pelo menos um cliente que ele atende além de EC. O cliente C3 é uma empresa que demanda os mesmos tipos de serviço de EC. O Entrevistado E3 considera em sua estratégia para ampliar a confiança de seu principal contratante a possibilidade de transferir sua conexão e assumir uma condição de posicionamento de ator isolado na Rede. Nessa posição isolada, ele pretende fortalecer o laço fraco com o ator de melhor posicionamento, o receptor do maior número de relações orientadas, pois sabe que não pode superar as barreiras institucionais em função de seus atributos - ao menos atualmente.

As formas de inserção na Rede acompanham as trajetórias profissionais dos profissionais de TI e a pesquisa empírica tem apontado para um cenário em que esta inserção pode ou não estar vinculada a formação acadêmica. A via de inserção dos entrevistados na amostra escolhida se dá pela condição de PJ, CLT ou informal (sem vínculo). No primeiro caso, isto é, os profissionais na condição de PJ que trabalham por projetos, na amostra dessa pesquisa atuam por contrato, sem jornada fixa estabelecida, sem garantias de direitos como férias remuneradas, por exemplo. Entre as exigências para inserção está um maior nível de formação e experiência por parte dos participantes dos projetos, principalmente nas fases iniciais ou nas primeiras atuações da empresa em processo de implantação das solicitações contratuais, como relata o Professor e Acionista (E9), com experiência como sócio de uma empresa de inovação.

No início da empresa era exigido um nível maior de formação dos participantes do projeto, em função da etapa de pesquisa e desenvolvimento. Porém, com o estabelecimento dos produtos e o perfil de clientes fidedignos, a necessidade por manter essa ampla capacidade de gerar conhecimento, ao menos novos conhecimentos, reduziu. $O$ estabelecimento do produto não exigia participação para elaboração de conhecimento, e sim de manutenção, podendo ser reduzido o grau de especialização ao nível de conhecimento técnico necessário para manutenção e melhora de performance. Nesse caso, um trabalhador 
mais voltado para o operacional, com possibilidade de menor remuneração em função das atividades a ser exercida. (Entrevista 09: Professor e Acionista, Bacharel em Informática, 46 anos, casado)

A fala atesta uma divisão do trabalho entre os operacionais, que, portanto, podem receber menos do que aqueles que trabalham nas etapas de elaboração. A hierarquia nesse caso não é vertical, mas horizontal em função das prioridades do arranjo do projeto e, na medida que o projeto avança e se consolida, as etapas finais tendem a ser mais padronizadas e replicadas, o que não parece diferente de outros processos de produção industrial. 0 conhecimento é absorvido em suas formas distintas, etapas de pesquisa com exigência de maior qualificação para criação e associação de novas ideias marcam o início do processo de desenvolvimento, e padronização. A busca por resultados funcionais desloca-se para o final e caracterizam também o direcionamento para a redução de custos. A flexibilidade do processo permite um ajuste quase que por completo da empresa conforme as circunstâncias pela qual está operando. Como veremos adiante, em certo momento a empresa de inovação poder operar sem um núcleo de pesquisa ativa, e, portanto, sem a necessidade de empregar profissionais com esse perfil.

Destacamos que a formação continuada, ou seja, o aperfeiçoamento em determinadas áreas por parte dos profissionais em Tecnologia da Informação (TI) é custeado, na maioria das vezes, pelos próprios profissionais, os quais percebem a necessidade de formação específica para sua permanência na participação de projetos em Rede. Algo que podemos observar no relato do Analista de Sistemas e Consultor em Segurança, PJ, 38 anos (E3)

[...] tem outras especializações que você pode fazer, por exemplo: banco de dados, cabeamento de Redes... o meu envolve meio que o geral, desde a área de cabeamento até a área de programação. Por exemplo: a faculdade hoje me ensinou muito programação, mas eu tenho certificação na área de banco de dados, cabeamento e na área de Linux. São as certificações que eu corri atrás e, na verdade ficou diversificado, [...] conheço bem de banco de dados, bastante de sistema operacional e segurança. Software na área de programação para mim é um diferencial que eu não pretendo seguir. (Entrevista 03: Analista de Sistemas e consultor em Segurança, graduando em Sistemas de Informação, 39 anos, casado)

Esse relato nos permite interpretar que os conhecimentos especializados podem não ser aplicados em determinado período de atuação, tornando-se apenas um potencial diferencial ou, de maneira contrária, uma restrição para participação em outras atividades que exijam formação específica. Desta forma algumas especialidades podem estar em alta enquanto outras ficam na fila das oportunidades, mas os profissionais de $\mathrm{TI}$ ainda mantêm os conhecimentos de base técnica, correspondentes a formação inicial, para continuarem ativos no mercado, fazendo a manutenção de sua permanência na Rede.

A complexidade da área de Tecnologia da Informação (TI) permitiu depararmo-nos com um grupo atuante, heterogêneo, dentro do qual encontram-se profissionais com formação acadêmica e profissionais com cursos técnicos profissionalizantes ou cursos livres na área da Tecnologia da Informação (TI), sem ensino superior.

Os laços fracos estabelecidos em momentos distintos da trajetória do trabalho mostram-se relevantes na manutenção de sua permanência na Rede. Outros recursos, como a disponibilidade de informações via Internet, contribuem para ampliação de sua Rede. 
Podemos dizer que além das principais formas de permanência nos projetos, encontramos também a necessidade da manutenção dos conhecimentos básicos em diversas áreas (dentro da TI) para a participação ativa em outras oportunidades dentro das empresas, como podemos observar no relato do entrevistado (03).

[...] sempre vai ter alguma coisa para fazer, seja no tablet... nós fazemos perícia desde aparelhos como smartphones, tablet, ipad [...] até câmera fotográfica. Você tem que entender de tudo um pouco, você não pode se dar ao luxo de dizer 'só conheço isso aqui', você não entra nesse mercado, [...]. Você tem que conhecer de tudo um pouco e, por exemplo, programação também ajuda bastante, por que eu, por exemplo, estou conhecendo linguagem Phyton - que a área de segurança usa muito, Java, acho que eu comentei com você, C - que os hackers usam muito. A gente tem que conhecer a cabeça dos caras, pensar como eles pensam. (Entrevista 03: Analista de Sistemas e consultor em Segurança, graduando em Sistemas de Informação, 39 anos, casado)

Na fala do Analistas de Sistemas e Consultor em Segurança, PJ, 38 anos (E3) é possível perceber a condição da necessidade de qualificação permanente. Ele entende que a qualificação por meio da aquisição de novos conhecimentos é uma condição, sem a qual não é possível superar barreiras de entrada no setor ou assegurar sua permanência. Esse cenário, comum no setor de TI, é a expressão de como a qualificação permanente tornou-se o pano de fundo que sustenta o modelo típico ideal na ideologia do novo capitalismo (Boltanski \& Chiapello, 2009; Sennett, 2006; Gorz, 2005).

Com a sobreposição da vida profissional em detrimento da vida privada, muitos profissionais acabam sofrendo penalidades no que tange à esfera pessoal, o que inclui realizar atividades do trabalho em casa, controlar o monitoramento de um projeto por meio de rádio ou celular empresarial (com atendimento 24 horas/dia) o que implica na invasão total da vida privada do profissional, como podemos observar no relato do entrevistado (03): Acontece de ter uma perícia para fazer final de semana, [...] embora eu não tenha contrato com ele, é o que eu volto a falar, é uma questão de comprometimento. Aí eu poderia chegar e falar que sábado eu não tenho tempo, ele iria aceitar e iria chamar outra pessoa, mas eu penso pelo lado seguinte: eu estou fazendo uma parceria com ele, então é uma responsabilidade, eu não vejo nem como obrigação, as vezes eu vejo alguns profissionais de carteira falar "eu tenho que trabalhar no sábado!", "cara, mas você é um trabalhador de carteira assinada e você é obrigado a trabalhar", "você, quando assinou a sua carteira, viu que ia trabalhar no sábado, não viu?" [...]. As vezes eu cito o meu exemplo: [...] eu não tenho vínculo empregatício nenhum com as empresas, mas eu tenho a questão de fidelidade com eles, eu poderia dizer "hoje eu não vou." "não estou a fim", "tenho um negócio para fazer" ou inventar alguma moda, mas acho que é uma questão até de profissionalismo e uma questão de reconhecimento com a pessoa, questão de amizade, "não, eu vou lá e vou fazer" e a empresa paga para mim por isso. (Entrevista 03: Analista de Sistemas e consultor em Segurança, graduando em Sistemas de Informação, 39 anos, casado)

O Analista de Sistemas e Consultor em Segurança (E3) aponta duas questões importantes: 1a) a

flexibilização da jornada de trabalho, demonstrando sua disponibilidade para trabalhar em finais de semana 
em ocasiões diversas e a ausência de vínculo empregatício, que supostamente daria autonomia para escolhas de atuação. Entretanto, analisamos a partir das entrevistas que a Rede se torna perversa quando as situações de natureza atípica com relação às atividades que extrapolam as jornadas ou os espaços de trabalho tornam-se fundamentais para a manutenção da participação desse ator (profissional) como ativo na Rede, como pudemos observar no relato acima. A chamada parceria em projetos torna borrada a fronteira entre espaços de trabalho e de não-trabalho, bem como os tempos destinados ao trabalho e ao não-trabalho em função daquilo que os profissionais entendem como comprometimento com o projeto. Outrossim, percebemos também uma falsa autonomia no que tange às estratégias de permanência, pois ao não atenderem os padrões de atuação estarão exclusos da Rede de profissionais, das oportunidades do setor.

\section{Conclusão}

A partir da amostra selecionada, buscamos dar destaque as estratégias de inserção e permanência na rede de trabalho a entrada e permanência de quatro profissionais no setor de TI. Estes profissionais enfrentam as forças das leis de oferta e demanda em um mercado específico, cujo fator de produção e mercadoria de troca é o conhecimento. Operam sobre o risco do insucesso permanente, quando não encontram mais oportunidades ou não estão mais dispostos a empenharem-se nessa atividade - nesses casos eles desaparecem da rede.

A adrenalina ou o entusiasmo do trabalho, embora os termos aqui pareçam estranhos, surgem como um elemento comum, como um fator motivador tanto para a escolha da profissão quanto para a readequação em diversas oportunidades, bem como no exercício de suas atividades. Rotinas de trabalho são situações a serem evitadas, longos projetos são considerados desgastantes e realizar a mesma atividade coloca os profissionais em situação de tédio e desmotivação. Isso foi algo destacado por dois de nossos entrevistados em posição de gerentes de projetos (Entrevistados 07 e09), em relação ao comportamento de profissionais sob sua subordinação.

Observando o histórico dos entrevistados foi possível notar a importância dos laços fortes no início da carreira desses profissionais. Em uma atividade que requer conhecimentos intensivos e seleciona os melhores candidatos dentro de um modelo concorrencial, é necessário destacar que o início de uma carreira geralmente é marcado por um baixo capital social, constituído prioritariamente por laços fortes, posto que há pouco conhecimento acumulado caracterizando menos possibilidades de contato para um ator fora do seu círculo familiar ou de amizade, ou quando esses não são substituídos pelas oportunidades formais de oferta de emprego: processos seletivos impessoais, editais e preenchimento de vagas ofertadas no mercado, sem mobilização de uma rede de contatos.

Para a análise estrutural da rede dos profissionais levamos em consideração a verificação das relações que os atores mantêm com seus contatos, com outros profissionais e instituições a que pertencem. A entrada de profissionais nas empresas se dá, conforme pudemos observar na fala dos quatro entrevistados, efetivamente pela indicação de ex-colega de trabalho ou amigo/parente e também por edital de oferta de vaga, direta ou por empresa especializada. Condição de oportunidade distintas conforme momento profissional desses atores individuais. 
O setor de TI apresenta-se como um campo amplo para realização de pesquisas empíricas e pode fornecer dados inovadores para compreensão das mudanças nas configurações de trabalho. A análise de redes sociais buscando a compreensão de como se dão as configurações das relações entre os atores individuais e coletivos mostra-se promissora para tornar evidente aspectos que legitimam novas formas de exploração do trabalho. 


\section{Referências}

Boltanski, L. \& Chiapello, E. (2009). O novo espírito do capitalismo. São Paulo: WMF Martins Fontes.

Bridi, M. A. (2011). Redes de empresas, trabalho e relações de trabalho no setor de informática no Paraná (Projeto de Pesquisa). UFPR, Curitiba.

Castells, M. (2007). Sociedade em rede (10ạa ed.). São Paulo: Paz e Terra.

Fligstein, N. (2009). Habilidade Social e Teoria dos Campos. In: A. C. B. Martes (Org.). Redes e sociologia econômica, (pp. 69-106). São Carlos: EdUFSCar.

Granovetter, M. (2009). Ação econômica e estrutura social: o problema da imersão. In: A. C. B. Martes (Org.), Redes e sociologia econômica, (pp. 31-68). São Carlos: EdUFSCar.

Gorz, A. (2005). O imaterial: conhecimento, valor e capital. Trad. Celso Azzan Júnior. São Paulo: Annablume.

Lallement, M. (2004). História das ideias sociológicas: de Parsons aos contemporâneos. Petrópolis: Vozes.

Lemieux, V. \& Ouimet, M. (2012). Análise Estrutural das Redes Sociais (2a ed.). Lisboa, PT: Instituto Piaget.

Martes, A. C. B. (Org.). (2009). Redes e sociologia econômica. São Carlos: EdUFSCar.

Murteira, M. (2004). Economia do Conhecimento. Rio de Janeiro: Quimera.

Sennett, R. (2006). A cultura do novo capitalismo. Rio de Janeiro: Record.

Sennett, R. (2012). A Corrosão do Caráter: O desaparecimento das virtudes com o novo capitalismo. Rio de Janeiro: BestBolso.

Souza, H. J. (2014). Como se faz análise de conjuntura (34a ed.). Petrópolis: Vozes.

Sperber, D. (1968). Le structuralisme en anthoropologie. In: O. Ducrot (Org.), Qu'est-ce que le structuralisme? (pp. 167-238). Paris: Seuil.

Swedberg, R. (2009). A Sociologia Econômica do Capitalismo: Uma introdução e agenda de pesquisa. In: A. C. B. Martes (Org.). Redes e sociologia econômica, (pp. 161-205). São Carlos: EdUFSCar. 